Cahiers $d u$ MONDE RUSSE

\section{Cahiers du monde russe}

Russie - Empire russe - Union soviétique et États indépendants

$48 / 4 \mid 2007$

Varia

\title{
Diane Skoda, La propriété dans le Code civil de la Fédération de Russie
}

\section{Aurore Chaigneau}

\section{(2) OpenEdition}

\section{Journals}

Édition électronique

URL : https://journals.openedition.org/monderusse/6108

DOI : 10.4000/monderusse. 6108

ISSN : $1777-5388$

Éditeur

Éditions de l'EHESS

\section{Édition imprimée}

Date de publication : 2 décembre 2007

Pagination : 787-789

ISBN : 978-2-7132-2148-4

ISSN : $1252-6576$

Référence électronique

Aurore Chaigneau, "Diane Skoda, La propriété dans le Code civil de la Fédération de Russie », Cahiers du monde russe [En ligne], 48/4 | 2007, mis en ligne le 16 juin 2009, consulté le 04 septembre 2022. URL : http://journals.openedition.org/monderusse/6108; DOI : https://doi.org/10.4000/monderusse. 6108

Ce document a été généré automatiquement le 4 septembre 2022.

Tous droits réservés 


\title{
Diane Skoda, La propriété dans le Code civil de la Fédération de Russie
}

\author{
Aurore Chaigneau
}

\section{RÉFÉRENCE}

Diane SKODA, La propriété dans le Code civil de la Fédération de Russie. Un système entre deux traditions. Paris : Dalloz, 2007, 756 p.

1 L'ouvrage de Diane Skoda a plusieurs mérites. Le premier, et non des moindres, tient à la qualité même de son auteur. Docteur en droit, Diane Skoda nous livre les réflexions d'une juriste sur les évolutions institutionnelles en Russie. Depuis la chute du régime soviétique, de profondes réformes juridiques ont accompagné les changements politiques, économiques et sociaux de la Fédération de Russie. Ils ont été largement étudiés en sciences sociales par les chercheurs européens et nord-américains. Plusieurs grilles de lecture en ont été proposées. Différents courants ont permis d'appréhender ces transformations contemporaines : à l'aune de la transitologie, par l'étude des trajectoires des élites et de leur path dependency, au prisme de l'analyse économiste institutionnaliste étudiant les pratiques formelles et informelles et les différents «marchés " plus ou moins institutionnalisés, les réseaux, etc. Les approches ethnologique et anthropologique enfin, par « en bas », voire par l'intime, ont mieux fait saisir les ressorts de l'action individuelle dans les profondeurs de l'Homo postsovieticus.

2 Mais sans dévaluer la grande fécondité de ces travaux, il est un instrument du changement de la société russe qui demeure mal étudié : son droit. Il serait abusif de dire qu'il n'est pas analysé. Quantité de travaux ont nécessité un recensement de la législation sur tel ou tel thème: que l'on se penche sur les associations, les autorités locales, les déportations, les entreprises, les pratiques de corruption ou le logement..., chaque fois la recherche bute sur une législation extraordinairement riche et complexe, voire même labyrinthique. Plus exactement, un droit omniprésent qui ne saurait se résumer à la loi, un droit qui se renouvelle dans la rupture, mais dont on ne cesse de souligner les 
continuités. Comment comprendre cet objet, véritable paradigme de la transformation de la Russie contemporaine? À la fois instrument de changement et lui-même en changement, le droit n'est-il pas dès lors à la fois outil et objet d'études? Largement utilisé comme outil dans les monographies, il l'est rarement comme objet. Or c'est bien là la tentative de Diane Skoda. Dans un État où le président Putin avait proclamé peu après sa prise de fonction «la dictature de la loi », cette recherche doit être prise au sérieux.

3 L'ouvrage se décompose en deux parties. La première est l'occasion de préciser le contexte dans lequel le droit de propriété a été pensé, à savoir la technique du droit ellemême et son contexte historique. La seconde est une étude détaillée des réformes du droit de propriété, au travers de la réécriture du Code civil et d'exemples dans deux domaines singuliers : le logement et la terre.

4 L'auteur procède d'abord à l'inventaire des différents cadres heuristiques couramment convoqués: transitologie, modernisation des institutions, rupture idéologique. Elle rappelle la complexité des traditions juridiques qui se sont croisées et sédimentées au cours de l'histoire russe. Les tensions générées par la "modernisation » au XIX ${ }^{e}$ siècle ou encore les spécificités de l'ordre juridique soviétique rendent ce droit si difficile à saisir. Tout cela impose de revisiter des catégories aussi fondamentales que la hiérarchie des normes, la notion de source du droit, de codification, etc. Parler de la législation soviétique sans un travail épistémologique préliminaire sur son statut conduit à de nombreux contresens, ce que l'on voit poindre aujourd'hui dans la littérature de jeunes juristes russes peu à même de contextualiser les règles et les travaux anciens dont ils font usage.

5 On regrettera que ces développements, véritablement passionnants, ne soient pas plus approfondis et que les critiques ne soient pas plus clairement formulées à l'encontre d'un certain nombre de préjugés sur le droit soviétique et prérévolutionnaire, notamment la prétendue existence d'une forme de propriété privée individuelle. Mais la tâche eût été considérable et là n'était sans doute pas l'objectif principal de l'auteur qui s'est focalisée sur le droit de propriété.

6 L'étude du droit de propriété met en lumière plusieurs évolutions. L'uniformisation des régimes de propriété en rupture avec le régime soviétique, la restauration de la distinction entre droit réel et droit de créance, de même que celle de meuble et d'immeuble. Elle étudie également les différentes formes de "propriété publique», notion disparue du vocabulaire soviétique mais que la doctrine s'est depuis réappropriée.

7 L'exploration du Code civil au travers des règles sur la possession, la prescription acquisitive et extinctive, de l'action en revendication, permet à tout un chacun de comprendre la technique du droit de propriété à la façon dont on étudie le droit français; et de voir comment le juriste systématise et donne sens aux multiples règles énumérées dans les pages du code.

8 Enfin, au travers des deux exemples choisis, le logement et la terre, nous comprenons mieux et les enjeux sous-jacents au choix des nouvelles règles et les difficultés à réformer si rapidement deux domaines qui furent au cœur des réformes économiques de la période contemporaine. On sait bien les évolutions progressives de la législation. L'auteur ne manque de signaler des enjeux connexes. Ainsi la réforme du statut du logement et celui de son occupant impliquait logiquement une révision de la propiska. De même, en matière immobilière, la vente de biens et la création d'un marché ont pour 
corollaire, voire pour préalable, la mise en place d'un cadastre nécessaire à la sécurisation des droits.

9 L'interdépendance des différentes réformes souligne bien l'effet systémique fort qu'induit le droit et, partant, nous invite à méditer sur son utilité dans une période de changements aussi importante que celle qu'a connue la Russie. Cet effet permet en conséquence de renoncer définitivement à l'idée qu'il aurait suffi de laisser faire la «main invisible » du marché. Les études sur les privatisations montrent très clairement l'importance des normes juridiques dans la création de marchés conditionnés par l'existence même de règles du jeu transparentes et publiques, ce que ne sont pas les règles « informelles » qui leur font parfois concurrence.

Il est une autre grave raison de s'intéresser à cette recherche. Diane Skoda a procédé à l'étude détaillée de certains arrêts de la Cour suprême et surtout de la Cour constitutionnelle dont elle nous restitue la substance. Or on ne saurait tout à fait comprendre le droit sans savoir comment il est appliqué. Les arrêts de la Cour constitutionnelle en particulier sont forts importants car la Cour a su prendre des positions souvent audacieuses en matière de propriété, abrogeant les conservatismes des autorités locales. Aujourd'hui, ces arrêts sont la base d'un véritable phénomène jurisprudentiel qui apporte la preuve de la vitalité des institutions russes. Ces arrêts des hautes juridictions sont étudiés et repris par les juridictions de tout le territoire de la Fédération. Ils permettent d'imposer une évolution des mentalités dans la pratique des organes judiciaires et servent tant aux magistrats qu'aux avocats. Cet ouvrage nous permet d'y accéder indirectement, en langue française, et de comprendre comment les hautes juridictions favorisent dans l'ombre du pouvoir la réforme des institutions. 